\title{
Características morfogênicas e estruturais do capim-marandu submetido a combinações de alturas e intervalos de corte
}

\author{
Gelson dos Santos Difante ${ }^{1^{*}}$, Domicio do Nascimento Júnior ${ }^{2}$, Sila Carneiro da Silva ${ }^{3}$, Valéria \\ Pacheco Batista Euclides ${ }^{4}$, Denise Baptaglin Montagner ${ }^{1}$, Márcia Cristina Teixeira da \\ Silveira ${ }^{1}$, Karine da Silva Pena ${ }^{1}$
}

\author{
1 Programa de Pós-Graduação em Zootecnia, Departamento de Zootecnia, UFV. \\ 2 Departamento de Zootecnia, UFV. \\ ${ }^{3}$ Departamento de Zootecnia, USP/ESALQ \\ ${ }^{4}$ Embrapa Gado de Corte.
}

RESUMO - Desenvolveu-se este estudo com o objetivo de avaliar o acúmulo de forragem e as características morfogênicas e estruturais do capim-marandu submetido a combinações de alturas e intervalos de corte. O experimento foi realizado no período de agosto de 2003 a abril de 2004. Os tratamentos corresponderam a combinações entre duas alturas (15 e $30 \mathrm{~cm}$ ) e três intervalos de corte (tempo correspondente para o aparecimento de três, quatro e cinco folhas por perfilho) e foram alocados às unidades experimentais em arranjo fatorial $2 \times 3$ e delineamento de blocos completos casualizados com três repetições. Foram avaliados o acúmulo total de forragem, o acúmulo de lâminas foliares, colmos e material morto, as variáveis morfogênicas e as estruturais, assim como a altura do dossel no pré-corte e a duração do período de rebrotação. O corte a $15 \mathrm{~cm}$ resultou em menor período de rebrotação, altura pré-corte, alongamento de colmo e tamanho final da folha e maior densidade populacional de perfilhos em comparação ao corte a $30 \mathrm{~cm}$. O intervalo de corte correspondente ao aparecimento de cinco folhas por perfilho resultou em maiores alturas pré-corte, taxas de alongamento de folhas, tamanho final das folhas e acúmulo de colmos e em menor densidade populacional de perfilhos em comparação aos intervalos correspondentes a três e quatro folhas surgidas por perfilho. A maior eficiência de utilização dos pastos de capim-marandu foi alcançada com cortes a $15 \mathrm{~cm}$. Pastos manejados com intervalo de corte correspondente a três folhas surgidas por perfilho, independentemente da altura de corte avaliada, acumulam elevada quantidade de folhas, componente altamente desejável para alimentação animal.

Palavras-chave: alongamento de folhas, altura do dossel, aparecimento de folhas, Brachiaria brizantha, ecofisiologia, produção de forragem

\section{Morphogenetic and structural characteristics of marandu palisadegrass subjected to combinations of cutting heights and cutting intervals}

\footnotetext{
ABSTRACT - The objective of this study was to evaluate forage accumulation and morphogenetic and structural characteristics of marandu palisadegrass subjected to combinations of cutting heights and cutting intervals. The experiment was carried out from August 2003 to April 2004. Treatments corresponded to combinations between two cutting heights (15 and $30 \mathrm{~cm}$ ) and three cutting intervals (time corresponding to the appearance of three, four and five new leaves per tiller), and they were allocated to experimental units according to a $2 \times 3$ factorial arrangement and a complete randomised block design, with three replications. It was evaluated accumulation of total forage, leaf blade, stem and dead material, morphogenetic and structural variables, as well as, pre-cut sward height and regrowth duration. Swards cut at $15 \mathrm{~cm}$ had shorter regrowth periods, pre-cut sward height, stem elongation rate and final leaf size, and larger tiller population density than swards cut at $30 \mathrm{~cm}$. The cutting interval corresponding to the appearance of five leaves per tiller resulted in higher pre-cut sward height, leaf elongation rate, final leaf size, stem accumulation and smaller tiller population density than those intervals corresponding to three and four leaves per tiller. The greatest utilization efficiency of marandu palisadegrass pastures was achieved with cuts at $15 \mathrm{~cm}$. Pastures managed with cutting intervals corresponding to three new leaves per tiller regardless of cutting height evaluated, accumulated high quantities of leaf, a highly desirable component for animal feeding purposes.
}

Key Words: Brachiaria brizantha, ecophysiology, forage production, leaf appearance, leaf elongation, sward height

Recebido em 5/12/2008 e aprovado em 20/05/2010 


\section{Introdução}

Atualmente, existem várias plantas forrageiras passíveis de se adequar aos mais diversos ecossistemas e formas de exploração (Lupinacci, 2003). O ecossistema pastagem é complexo e seus componentes bióticos e abióticos interagem entre si de diferentes maneiras. Para compreensão das respostas das plantas ao pastejo, torna-se essencial que parâmetros relacionados à sua ecofisiologia sejam avaliados quando submetidas a regimes de desfolhação. Idealmente, deve-se procurar o equilíbrio entre a manutenção de área foliar suficiente para fotossíntese e a colheita de grandes quantidades de folhas antes que estas venham a senescer, de forma a favorecer uma exploração racional e eficiente das pastagens. A essência do manejo de áreas de pastagens corresponde à obtenção de um balanço harmônico entre as eficiências dos três principais estágios de produção: crescimento do pasto, colheita da forragem produzida e conversão da forragem colhida em produto animal (Hodgson, 1990).

A compreensão dos efeitos do pastejo sobre a planta requer conhecimento e análise das alterações morfológicas e fisiológicas provocadas por esse processo. Esses são consequências da severidade e frequência de desfolhação, do tempo de rebrotação (no caso de pastejo rotativo) e da interação entre desfolhação e fatores ambientais, ou seja, disponibilidade hídrica e de nutrientes, intensidade luminosa e estádio fenológico das plantas.

O conhecimento da ecofisiologia de plantas forrageiras submetidas ao corte ou pastejo constitui-se, portanto, um desafio ao pesquisador, pois as práticas de manejo adotadas alteram de forma marcante e diferenciada cada espécie forrageira e plantas individuais, refletindo-se sobre a população de plantas e a capacidade produtiva do pasto (Sbrissia et al., 2007).

Realizou-se este estudo com o objetivo de avaliar o acúmulo total de forragem, o acúmulo de lâminas foliares, de colmos e de material morto e as respostas morfogênicas (taxas de aparecimento e alongamento de folhas, alongamento de colmos e duração de vida da folha) e estruturais (relação lâmina:colmo, comprimento final da folha, densidade populacional de perfilhos e número de folhas vivas por perfilho) do capim-marandu submetido a regimes de corte.

\section{Material e Métodos}

O experimento foi conduzido em área do Departamento de Zootecnia da Universidade Federal de Viçosa, Minas
Gerais, no período de agosto de 2003 a abril de 2004. O clima da região, segundo a classificação de Köppen, é Cwa, subtropical, com estações seca e chuvosa bem definidas. Os dados climáticos (Figura 1) foram obtidos na estação meteorológica do Departamento de Engenharia Agrícola, localizada a cerca de $1.000 \mathrm{~m}$ do local do experimento.

O solo da área experimental é classificado como Argissolo vermelho amarelo de textura franco-argilosa (EMBRAPA, 1999). Foram realizadas amostragens na camada de zero a $20 \mathrm{~cm}$ para análise da fertilidade do solo, realizadas no laboratório do Departamento de Solos da UFV. Os resultados obtidos foram: $\mathrm{pH}\left(\mathrm{H}_{2} \mathrm{O}\right)=5,8$; $\mathrm{Ca}$ $\left(\mathrm{cmol}_{\mathrm{c}} / \mathrm{dm}^{3}\right)=3,2 ; \mathrm{Mg}\left(\mathrm{cmol}_{\mathrm{c}} / \mathrm{dm}^{3}\right)=0,9 ; \mathrm{Al}\left(\mathrm{cmol}_{\mathrm{C}} / \mathrm{dm}^{3}\right)=$ zero; $\mathrm{H}+\mathrm{Al}\left(\mathrm{cmol}_{\mathrm{c}} / \mathrm{dm}^{3}\right)=6,1$; Soma de bases $\left(\mathrm{cmol}_{\mathrm{c}} / \mathrm{dm}^{3}\right)=$ 4,3; CTC $\left(\mathrm{cmol}_{\mathrm{C}} / \mathrm{dm}^{3}\right)=10,4$; Saturação por alumínio $(\%)=$ zero; Saturação por bases $(\%)=41,2 ; \mathrm{P}-\operatorname{Mehlich}^{-1}\left(\mathrm{mg} / \mathrm{dm}^{3}\right)=$ 1,8; K-Mehlich ${ }^{-1}\left(\mathrm{mg} / \mathrm{dm}^{3}\right)=24,0$. Foi aplicado 1,1 $\mathrm{t} / \mathrm{ha} \mathrm{de}$ calcário dolomítico (PRNT = 83\%) com o objetivo de elevar a saturação por bases para 50\%. A adubação fosfatada, na forma de superfosfato simples, foi realizada no momento da transplantação das mudas para a área experimental e o fertilizante foi aplicado em linha na quantidade de $100 \mathrm{~kg} / \mathrm{ha}$.

As sementes de Brachiaria brizantha cv. Marandu foram semeadas no mês de agosto em bandejas plásticas contendo substrato orgânico comercial e foram mantidas em casa-de-vegetação com irrigação diária até a transplantação para a área experimental, no dia 16 de setembro de 2003. Foram utilizadas parcelas de $0,60 \mathrm{~m}^{2}$ $(0,60 \times 1,00 \mathrm{~m})$ com um estande de 24 plantas por parcela e espaçamento de $20 \mathrm{~cm}$ entre linhas e $15 \mathrm{~cm}$ entre plantas. Após o completo estabelecimento (45 dias após a semeadura), as plantas foram submetidas a um corte de uniformização a $15 \mathrm{~cm}$ de altura do solo. O corte referente aos tratamentos foi realizado 30 dias após o corte de uniformização, época em que foram aplicados $50 \mathrm{~kg} / \mathrm{ha}$ de nitrogênio na forma de uréia. As avaliações das características morfogênicas e estruturais do dossel foram iniciadas no dia 24 de outubro de 2003.

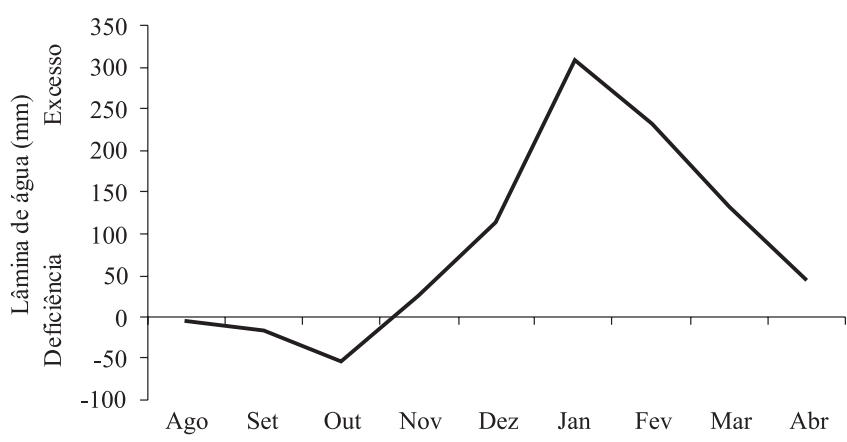

Figura 1 - Extrato do balanço hídrico mensal ocorrido durante o período experimental (Thornthwaite \& Mather, 1955). 
Foram avaliadas combinações entre duas alturas (15 e $30 \mathrm{~cm}$ ) e três intervalos de corte (tempo necessário para o aparecimento de três, quatro e cinco novas folhas por perfilho), alocados às unidades experimentais (parcelas de $0,60 \mathrm{~m}^{2}$ ) segundo um arranjo fatorial $2 \times 3$ em delineamento de blocos completos casualizados, com três repetições.

As datas de corte foram determinadas por meio do número de folhas surgidas nos perfilhos marcados para o acompanhamento da morfogênese. Quando a média dos perfilhos do tratamento (combinação entre altura e intervalo de corte), independentemente dos blocos, atingia o número predeterminado de folhas surgidas, eram realizados os cortes e as datas registradas. Antes de cada corte, foi mensurada a altura do dossel em três pontos aleatórios por parcela utilizando-se uma régua graduada em centímetros. As leituras foram feitas com a régua posicionada sobre a superfície do solo e adotando-se como referência o horizonte das folhas ao redor da régua.

Para avaliação do acúmulo de forragem e da relação lâmina:colmo, quatro plantas por parcela foram cortadas acima das alturas de corte avaliadas $(15$ e $30 \mathrm{~cm})$. As amostras foram separadas manualmente em lâminas foliares, colmos (colmos + bainhas foliares) e material morto, acondicionadas em sacos de papel, pesadas e depois encaminhadas para secagem em estufa de ventilação forçada a $60^{\circ} \mathrm{C}$ até atingirem peso constante, quando foram novamente pesadas. $\mathrm{O}$ acúmulo total de forragem, de lâminas foliares, de colmos e de material morto foi obtido pela transformação do peso seco das amostras em kg/m². A relação lâmina:colmo foi calculada como sendo o quociente entre a massa seca de lâminas foliares e a massa seca de colmos.

As variáveis morfogênicas e estruturais do capimmarandu foram avaliadas utilizando-se perfilhos marcados com fios coloridos em duas touceiras escolhidas aleatoriamente por parcela. Duas vezes por semana foram tomados os valores de alongamento e aparecimento foliar, alongamento do colmo e senescência foliar. Com base nos dados de campo foram calculadas as taxas de aparecimento de folhas (folhas/perfilho.dia), alongamento de folhas (cm/perfilho.dia), senescência foliar (cm/perfilho.dia) e alongamento de colmos ( $\mathrm{cm} /$ perfilho.dia), o número de folhas vivas por perfilho (folhas/perfilho), a duração de vida das folhas, em dias (Lemaire \& Chapman, 1996), o comprimento final das folhas (cm/folha) e o filocrono (dias).

Os dados foram submetidos à análise de variância utilizando o esquema fatorial em parcelas subdivididas no tempo, em que os tratamentos constituíram as parcelas e os cortes as subparcelas. Utilizou-se o procedimento GLM e os comandos RANDOM e TEST do pacote estatístico SAS (SAS Institute, 1996). A comparação de médias, quando necessária, foi realizada por meio de contrastes tanto para os efeitos principais de altura e intervalo de corte quanto para os efeitos da interação altura vs intervalo de corte, adotando-se nível de 5\% de significância.

Para as variáveis período de rebrotação e densidade populacional de perfilhos, foi utilizado o seguinte modelo: Yijk $=\mu+F i+I j+F I i j+C k+e i j k$,

em que: Yijk = valor observado do intervalo i e altura j no corte $\mathrm{k} ; \mu$ = constante geral (média da população); $\mathrm{Fi}$ = efeito do intervalo de corte i, i = 1, 2, 3; $I j=$ efeito da altura j, $\mathrm{j}=1$, 2; FIij = interação intervalo i e altura j; $\mathrm{Ck}=$ efeito do corte $\mathrm{k}, \mathrm{k}=1$, 2, 3, 4; e eijk = erro aleatório associado a cada observação Yijk.

Para as variáveis altura pré-corte do dossel, características morfogênicas e estruturais e acúmulo de forragem, utilizou-se o modelo:

Yijkl $=\mu+F i+I j+F I i j+e a+C l(F I i j)+e b$, em que: $Y i j k l=$ valor observado do intervalo $\mathrm{i}$, altura j e bloco k no corte l; $\mu$ = constante geral (média da população); $\mathrm{Fi}$ = efeito do intervalo de corte i, i = 1, 2, 3; Ij = efeito da altura j, j = 1, 2; FIij = interação intervalo i e altura j; ea = FIBijk, erro em que Fi, Ij e FIij foram testados; Bk = efeito do bloco k, $\mathrm{k}=1,2,3 ; \mathrm{Cl}(\mathrm{FIij})=$ efeito do corte $\mathrm{l}$, aninhado à interação FIij, l = 1, 2, 3, 4; e eb = BCkl(FIij), erro em que Cl(FIij) foi testado.

\section{Resultados e Discussão}

O período de rebrotação não foi afetado pela interação altura vs intervalo de corte ( $\mathrm{P}=0,7931)$, mas variou com o intervalo de corte $(\mathrm{P}=0,0104)$. O maior período de rebrotação foi registrado nas plantas cortadas com o intervalo de corte de cinco folhas surgidas por perfilho (Figura 2).

Foram realizados quatro, três e dois cortes durante todo o período experimental para os intervalos de três, quatro e cinco folhas surgidas por perfilho, respectivamente, independentemente da altura de corte avaliada $(15$ ou $30 \mathrm{~cm}$, Figura 3).

A remoção da massa de forragem pelo corte ou pastejo desencadeia mecanismos que controlam alterações morfológicas das plantas forrageiras (parte aérea), as quais variam conforme a duração e a intensidade do processo de desfolhação (Sbrissia et al., 2007). Neste experimento, o período de rebrotação variou apenas com o intervalo de corte, indicando que as alturas de corte avaliadas não foram drásticas ou lenientes o suficiente para comprometer a recuperação das plantas (Figura 3).

A altura pré-corte do dossel variou com a altura ( $\mathrm{P}<0,0001)$ e o intervalo de corte $(\mathrm{P}<0,0001)$, mas não foi detectada interação altura vs intervalo de corte $(\mathrm{P}=0,1630)$. 


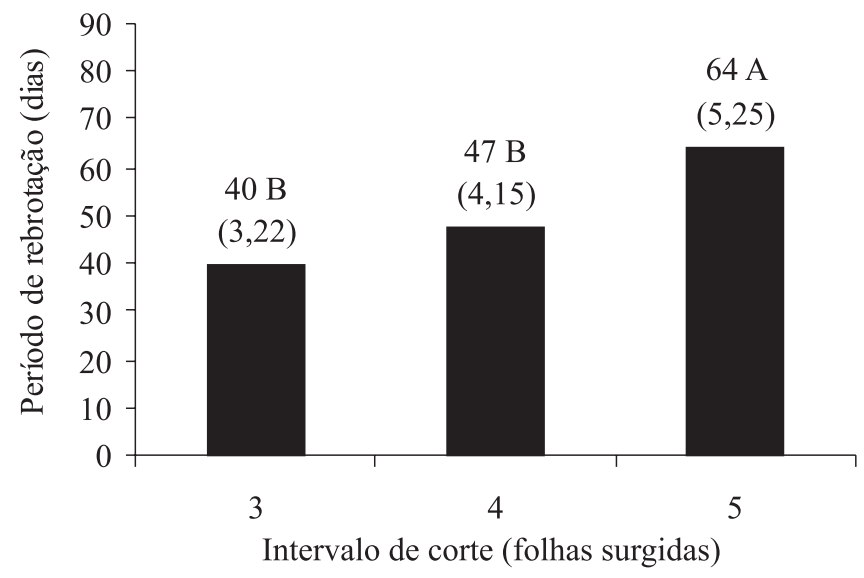

Médias seguidas por letras maiúsculas distintas diferem $(\mathrm{P}<0,05)$ entre si pelo teste de Tukey.

Valores entre parênteses correspondem ao erro padrão da média (EPM).

Figura 2 - Período de rebrotação médio (dias) em cada intervalo de corte.

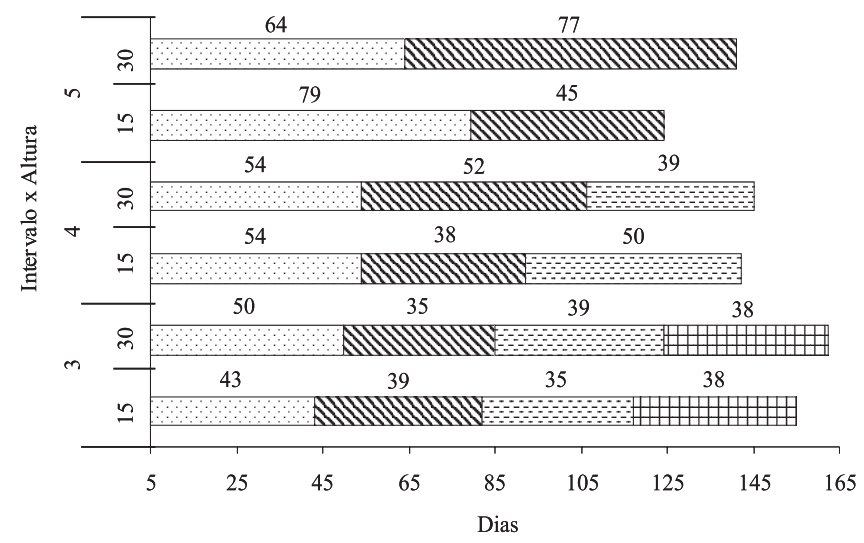

Figura 3 - Duração do período de rebrotação (dias) em cada combinação de altura e intervalo de corte.

Os maiores valores de altura pré-corte foram registrados nas plantas cortadas a $30 \mathrm{~cm}$ (Figura 4A) ou segundo o aparecimento de cinco folhas por perfilho (Figura 4B).

O primeiro efeito da desfolhação é uma resposta plástica da planta para a adaptação às modificações em seu ambiente. O manejo da desfolhação induz modificações na quantidade e qualidade da luz que chega às folhas mais próximas do solo (Deregibus et al., 1985), determinando variações no perfilhamento (Lemaire \& Agnusdei, 2000). Neste experimento, a altura de corte de $15 \mathrm{~cm}$ assegurou às plantas maior quantidade de radiação solar de melhor qualidade nas folhas próximas ao solo, ativando assim as gemas dormentes e aumentando o aparecimento de novos perfilhos.

No caso do menor intervalo de corte (três folhas surgidas por perfilho), a competição por luz deve ter sido pequena
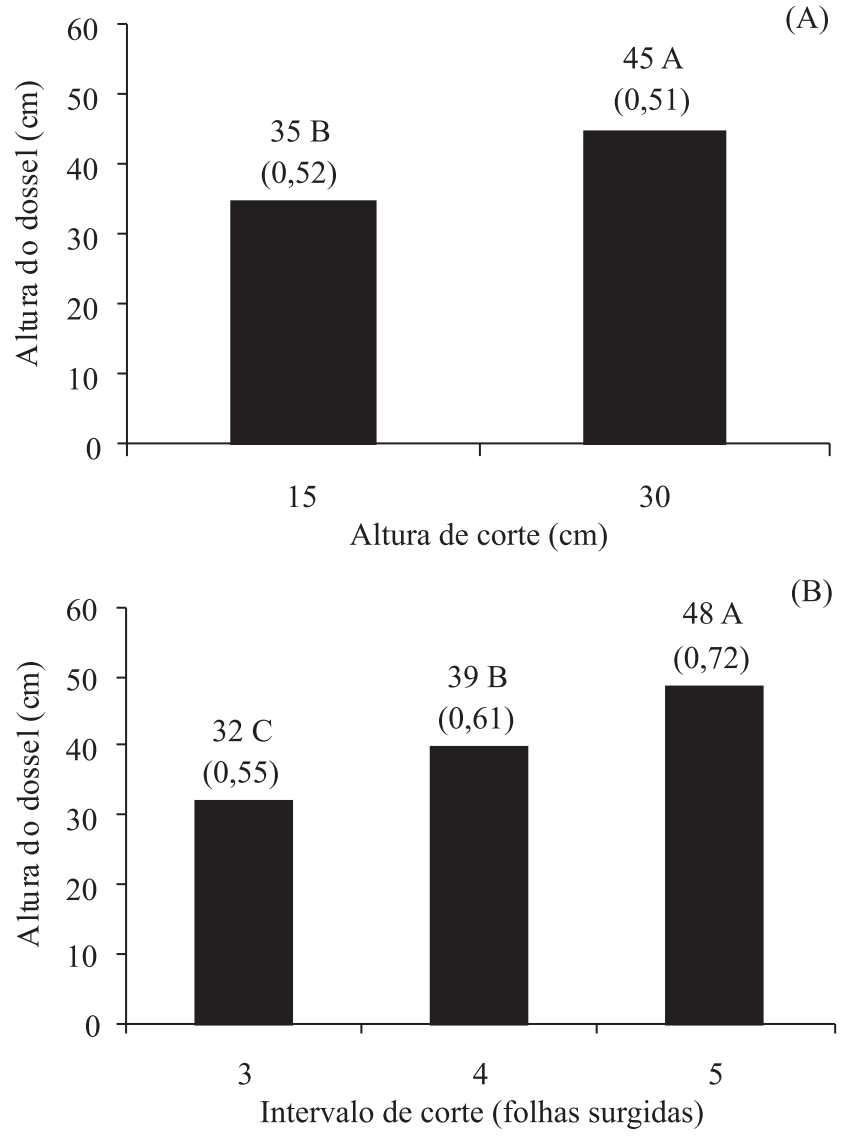

Médias seguidas de letras maiúsculas distintas diferem $(\mathrm{P}<0,05)$ entre si pelo teste de Tukey.

Valores entre parênteses correspondem ao erro padrão da média (EPM).

Figura 4 - Altura pré-corte $(\mathrm{cm})$ do capim-marandu submetido a combinações de altura (A) e intervalo de corte (B).

devido à frequente remoção da área foliar (Sbrissia et al., 2007). Nessas condições as plantas tendem a desenvolver folhas mais curtas, de forma que a associação entre a altura de corte de $15 \mathrm{~cm}$ e o intervalo de corte de três folhas surgidas por perfilho resultou em modificações no tamanho e número dos perfilhos e no tamanho das folhas, respectivamente, que resultaram em menores valores de altura pré-corte das plantas (Figura 4B).

Por outro lado, com a altura de corte de $30 \mathrm{~cm}$, as plantas priorizaram o crescimento de perfilhos existentes, uma vez que a quantidade e a qualidade da radiação solar chegando à base das plantas deve ter sido menor, fato que reduz significativamente o aparecimento de novos perfilhos (Matthew et al., 1999). No caso do maior intervalo de corte (cinco folhas surgidas por perfilho), a competição por luz deve ter aumentado continuamente durante o período de rebrotação sendo que a cada corte deve ter ocorrido uma rápida modificação tanto na quantidade como na qualidade da luz que chegava à base das plantas assim como na estrutura do dossel. 
Nessas condições as plantas tendem a desenvolver folhas mais longas e reduzir o perfilhamento (Nelson, 2000), situação que resulta em pastos de menor densidade populacional de perfilhos, porém com perfilhos maiores e mais pesados. Dessa forma, a associação entre a altura de corte de $30 \mathrm{~cm}$ e o intervalo de corte de cinco folhas surgidas por perfilhos deve ter resultado em redução do perfilhamento, aumento da mortalidade de perfilhos jovens e também aumento do comprimento final das folhas, resultando em maiores valores de altura pré-corte das plantas (Figura 4B).

Resultados recentes com capim-marandu submetidos a estratégias de pastejo rotativo (Trindade et al., 2007) mostraram que o momento ideal para interrupção da rebrotação dos pastos esteve associado ao ponto em que o dossel interceptava 95\% da luz incidente, e que este correspondeu a uma altura pré-pastejo de aproximadamente $25 \mathrm{~cm}$, menor que as alturas pré-corte obtidas neste experimento. Dessa maneira, mesmo o menor intervalo de corte testado, de três folhas surgidas por perfilho, deve ter sido mais longo que o ideal para colheita da forragem, uma vez que a altura pré-corte foi de $32 \mathrm{~cm}$ (Figura 4A) e o período de rebrotação de 40 dias (Figura 3) são maiores que aqueles obtidos quando o capim-marandu é colhido com 95\% de interceptação de luz $(25 \mathrm{~cm})$ e rebaixado a $15 \mathrm{~cm}$ (Souza-Júnior, 2007).

Cabe ressaltar que a altura de resíduo de $15 \mathrm{~cm}$ foi considerada ideal para o manejo do capim-marandu (Trindade et al., 2007), sugerindo que o manejo do pastejo desse cultivar deva ser realizado de forma mais frequente e intensa do que normalmente utilizado, potencializando o acúmulo de folhas e favorecendo o desempenho animal.

O acúmulo de forragem e de seus componentes morfológicos variou com os regimes de corte avaliados. Houve interação entre intervalo e altura de corte $(\mathrm{P}<0,05)$ para acúmulo total de forragem, de lâminas foliares e de material morto. $\mathrm{O}$ acúmulo de colmos diferiu apenas entre intervalos de corte $(\mathrm{P}<0,0001)$ e foi maior quando as plantas foram cortadas após o surgimento de cinco folhas por perfilho (0,6; 0,9; e 2,3 kg/m² de MS para três, quatro e cinco folhas novas surgidas por perfilho, respectivamente). Para os intervalos de corte correspondentes ao surgimento de três e quatro folhas por perfilho não houve diferença em acúmulo total de forragem, de lâminas foliares e material morto entre as alturas de corte avaliadas (Tabela 1).

Quando o intervalo de corte foi maior, correspondente a cinco folhas surgidas por perfilho, as plantas cortadas a $30 \mathrm{~cm}$ apresentaram maior acúmulo total de forragem, consequência do maior acúmulo de lâminas foliares (TApF = taxa de aparecimento de folhas e $\mathrm{TAlF}=$ taxa de alongamento de folhas; Figura 5), mas, também, do maior acúmulo de colmos. O acúmulo de material morto foi alto nas plantas cortadas a $30 \mathrm{~cm}$ a cada cinco folhas surgidas por perfilho durante a rebrotação, fato coerente com os maiores valores de taxa de senescência foliar registrados sob aquelas circunstâncias.

O acúmulo total de forragem foi composto de $46 \%$ de lâminas foliares, $37 \%$ de colmos e $18 \%$ de material morto quando o intervalo de corte foi de cinco folhas surgidas por perfilho. Por outro lado, quando o capim-marandu foi cortado com o intervalo de três folhas surgidas por perfilho, a composição foi de $60 \%$ de lâminas foliares, $23 \%$ de colmos e $15 \%$ de material morto, fato que indica que as plantas cortadas a $30 \mathrm{~cm}$ após o surgimento de cinco folhas por perfilho foram mais produtivas, mas, contudo, apresentaram maior participação de colmos e de material morto na forragem produzida, componentes esses que dificultam a capacidade de apreensão de forragem e, conseqüentemente, o consumo voluntário de animais em pastejo, podendo comprometer a eficiência de utilização da forragem produzida. Além disso, a eficiência de utilização das plantas cortadas a 15 cm após o surgimento de três ou quatro folhas por perfilho é maior (Figura 3) quando comparados à combinação de $30 \mathrm{~cm}$ de altura de corte e cinco folhas surgidas. Resultados semelhantes relativos ao acúmulo de forragem em capimmarandu foram reportados por Marcelino et al. (2006), em experimento onde se avaliou duas alturas $(10$ e $20 \mathrm{~cm}$ ) e três intervalos de corte (tempo necessário para o surgimento de cinco, sete e nove folhas por perfilho).

As respostas morfogênicas do capim-marandu foram afetadas de maneiras diferentes pelos regimes de corte avaliados. Houve interação entre altura e intervalo de corte $(\mathrm{P}=0,0459)$ para a taxa de aparecimento de folhas (Figuras 5 e 6 ).

Tabela 1 - Acúmulo total de forragem, de lâminas foliares e de material morto em capim-marandu submetido a combinações de intervalos e alturas de corte

\begin{tabular}{|c|c|c|c|}
\hline \multirow[t]{2}{*}{ Altura $(\mathrm{cm})$} & \multicolumn{3}{|c|}{ Intervalo (folhas surgidas) } \\
\hline & 3 & 4 & 5 \\
\hline & \multicolumn{3}{|c|}{ Acúmulo total de forragem $\left(\mathrm{kg} / \mathrm{m}^{2}\right.$ de $\left.\mathrm{MS}\right)$} \\
\hline 15 & $2,9 \mathrm{Ab}(0,32)$ & $3,3 \mathrm{Ab}(0,41)$ & $5,0 \mathrm{Ba}(0,55)$ \\
\hline \multirow[t]{2}{*}{30} & $2,3 \mathrm{Ac}(0,32)$ & $3,6 \mathrm{Ab}(0,41)$ & $7,5 \mathrm{Aa}(0,55)$ \\
\hline & \multicolumn{3}{|c|}{ Acúmulo de lâminas foliares $\left(\mathrm{kg} / \mathrm{m}^{2}\right.$ de $\left.\mathrm{MS}\right)$} \\
\hline 15 & $1,6 \mathrm{Ab}(0,12)$ & $1,6 \mathrm{Ab}(0,15)$ & $2,3 \mathrm{Ba}(0,20)$ \\
\hline \multirow[t]{2}{*}{30} & $1,5 \operatorname{Ac}(0,12)$ & $2,0 \mathrm{Ab}(0,15)$ & $3,4 \mathrm{Aa}(0,20)$ \\
\hline & \multicolumn{3}{|c|}{ Acúmulo de material morto $\left(\mathrm{kg} / \mathrm{m}^{2}\right.$ de $\left.\mathrm{MS}\right)$} \\
\hline 15 & $0,5 \mathrm{Aa}(0,07)$ & $0,7 \mathrm{Aa}(0,09)$ & $0,9 \mathrm{Aa}(0,12)$ \\
\hline 30 & $0,3 \mathrm{Ab}(0,07)$ & $0,5 \mathrm{Ab}(0,09)$ & $1,4 \mathrm{Aa}(0,12)$ \\
\hline
\end{tabular}

Médias seguidas de letras maiúsculas distintas, na mesma coluna, diferem $(\mathrm{P}<0,05)$ entre si.

Médias seguidas de letras minúsculas distintas, na mesma linha, diferem $(\mathrm{P}<0,05)$ entre si.

Valores entre parênteses correspondem ao erro-padrão da média (EPM). 


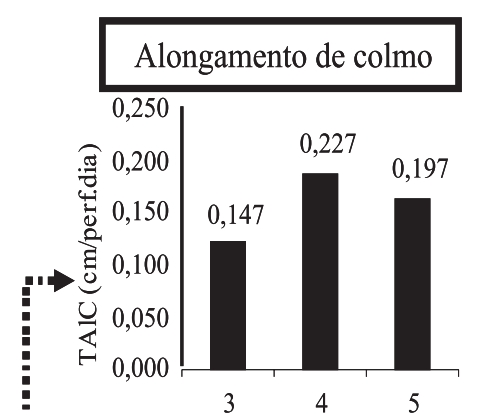

Intervalo de corte (folhas surgidas)

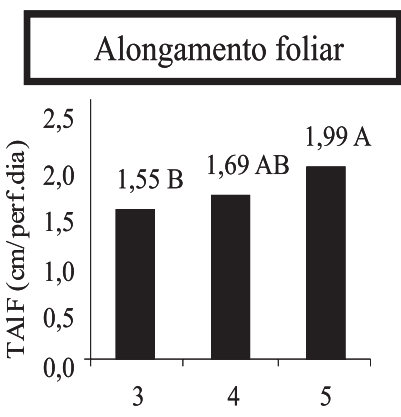

Intervalo de corte (folhas surgidas)

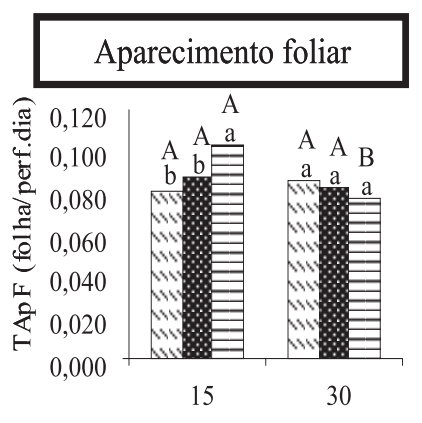

Intervalo de corte (folhas surgidas)
Duração de vida da folha

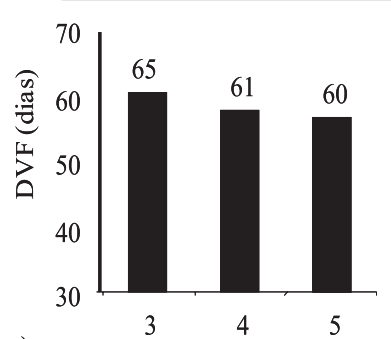

Intervalo de corte (folhas surgidas)
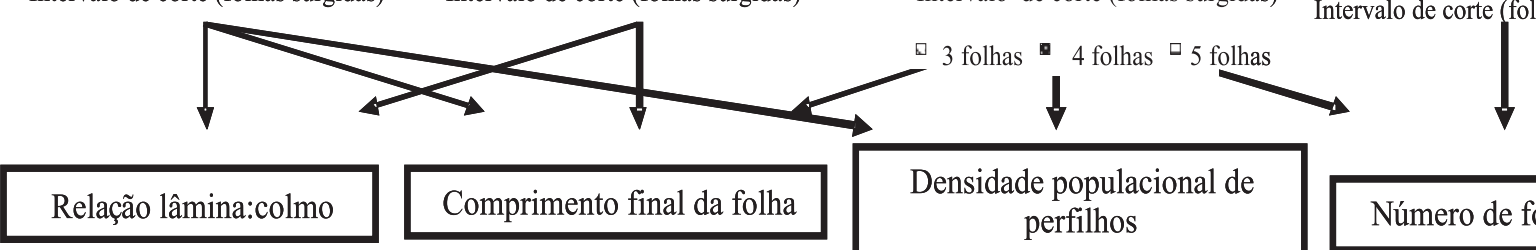

Número de folhas vivas
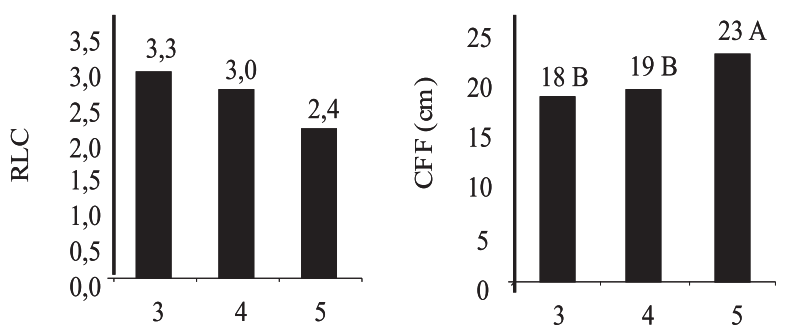

Intervalo de corte (folhas surgidas)

Intervalo de corte (folhas surgidas)

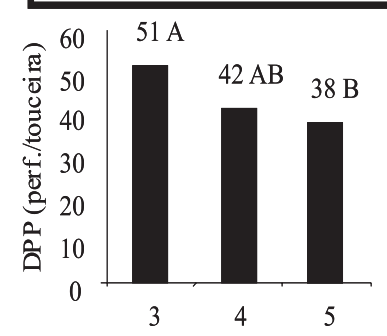

Intervalo de corte (folhas surgidas)

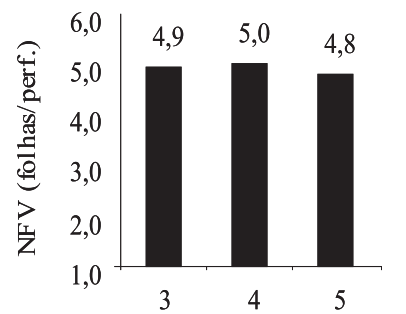

Intervalo de corte (folhas surgidas)
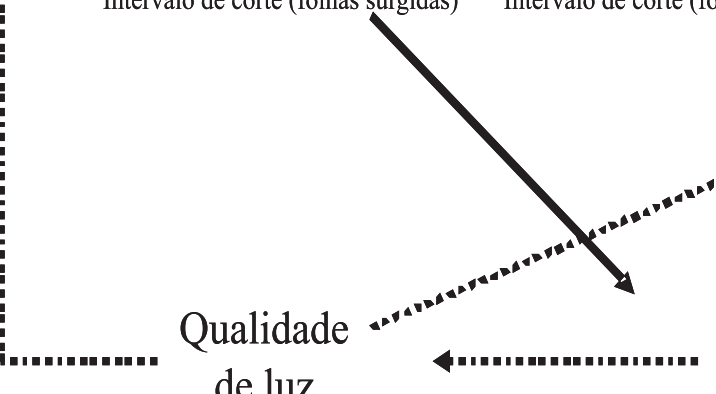

de luz
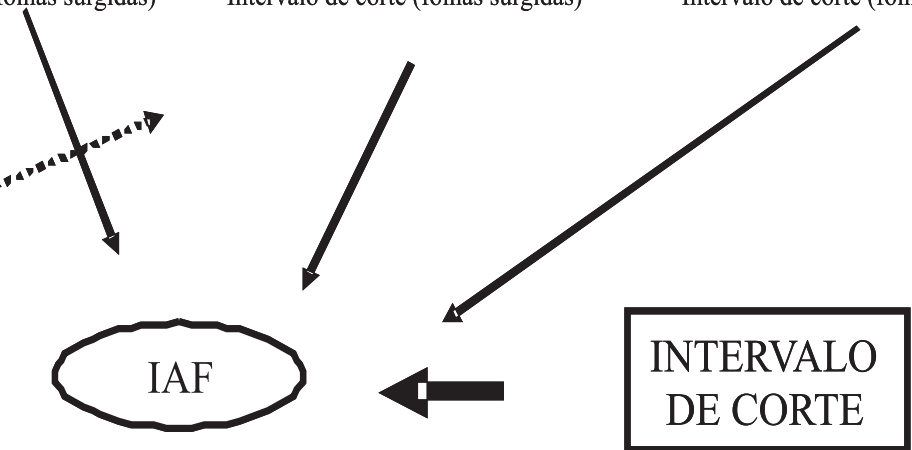

Médias seguidas por letras maiúsculas distintas diferem $(\mathrm{P}<0,05)$ entre si pelo teste de Tukey.

Para a TApF, letras maiúsculas distintas indicam diferenças entre alturas dentro de intervalo de corte e letras minúsculas indicam diferenças ( $<<0,05)$ entre intervalos dentro de altura de corte.

Figura 5 - Características morfogênicas e estruturais do dossel em cada intervalo de corte.

Com relação ao intervalo de corte, as variáveis taxa de alongamento de colmos $(\mathrm{P}=0,0606)$, duração de vida das folhas ( $\mathrm{P}=0,6697)$, relação lâmina:colmos ( $\mathrm{P}=0$,3885) enúmero de folhas vivas $(0,8973)$ não foram afetadas, diferentemente da taxa de alongamento foliar $(\mathrm{P}=0,0204)$, comprimento final da folha $(\mathrm{P}=0,0001)$ e densidade populacional de perfilhos ( $\mathrm{P}=0$,0457) (Figura 5). Já com relação à altura de corte, as variáveis taxa de alongamento foliar $(\mathrm{P}=0,9042)$, duração de vida das folhas ( $\mathrm{P}=0,5453)$, relação lâmina:colmo ( $\mathrm{P}=0,0768)$ e número de folhas vivas $(\mathrm{P}=0,1594)$ não foram afetadas, o oposto acontecendo com taxa de alongamento de colmos $(\mathrm{P}=0,0284)$, comprimento final da folha
( $P<0,0001)$ e densidade populacional de perfilhos $(\mathrm{P}=0,0132)$ (Figura 6).

A morfogênese pode ser definida como a dinâmica de geração e expansão da forma da planta no espaço (Chapman \& Lemaire, 1993). As taxas de aparecimento e alongamento de folhas, duração de vida das folhas (Chapman \& Lemaire, 1996) e a taxa de alongamento de colmos (Sbrissia \& Da Silva, 2001) são consideradas características morfogênicas de pastos tropicais e sofrem influência da temperatura, suprimento de nutrientes, umidade do solo e determinam as características estruturais. O produto das características estruturais determina o índice de área foliar do pasto, que 


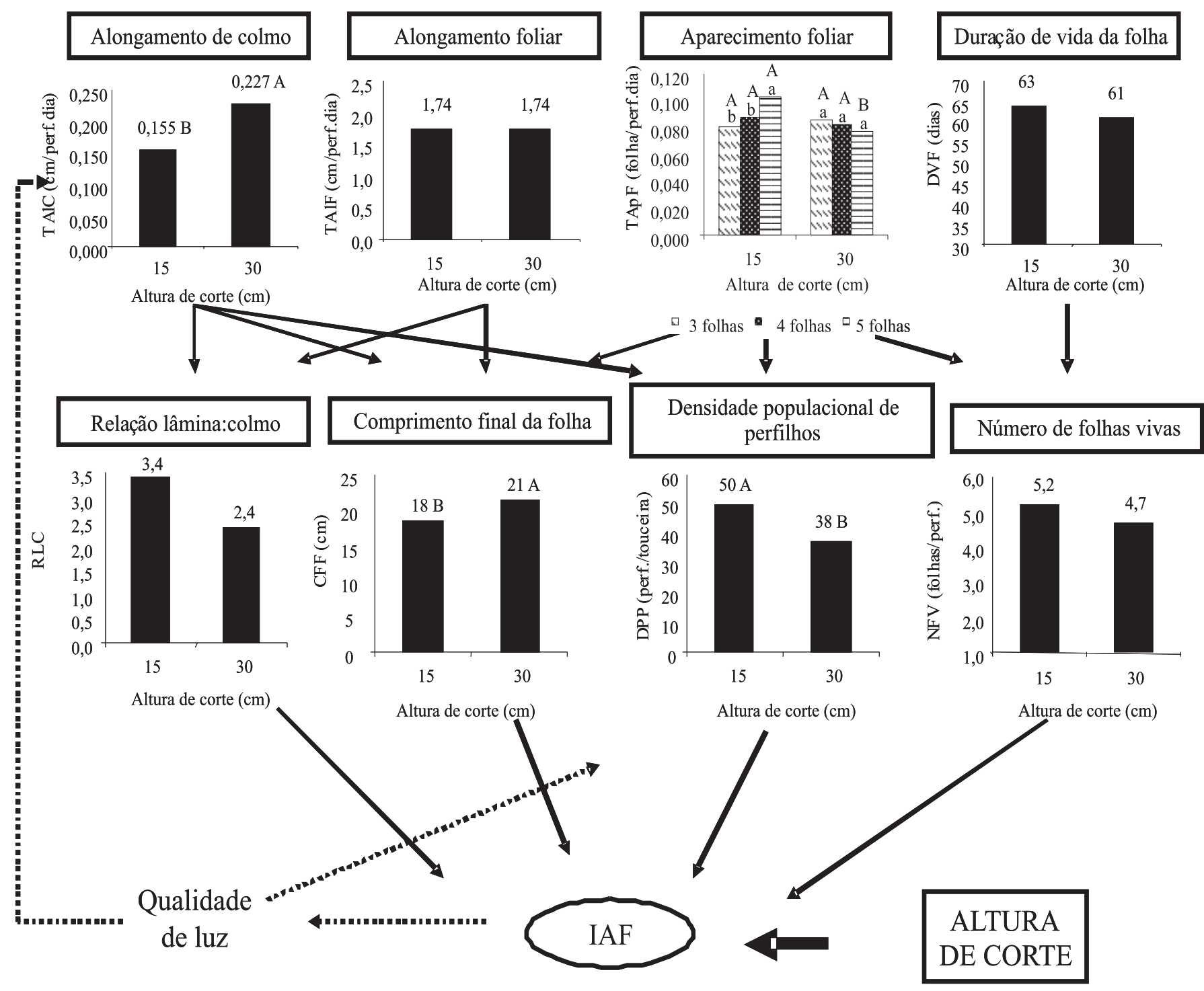

Médias seguidas de letras maiúsculas distintas diferem $(\mathrm{P}<0,05)$ entre si pelo teste de Tukey.

Para a TApF, letras maiúsculas distintas indicam diferenças entre alturas dentro de intervalo de corte e letras minúsculas indicam diferenças ( $<<0,05)$ entre intervalos dentro de altura de corte.

Figura 6 - Características morfogênicas e estruturais do dossel de acordo com as alturas de corte.

possui alta correlação com as respostas de plantas e animais no ambiente de pastagem e é modificado pelo manejo do pastejo.

A taxa de aparecimento de folhas é considerada a característica central da morfogênese, uma vez que influencia diretamente cada um dos componentes estruturais e, consequentemente, o índice de área foliar do pasto. O manejo do capim-marandu com menor altura e maior intervalo entre corte (15 cm e cinco folhas surgidas por perfilho) promoveu a maior taxa de aparecimento foliar, embora tenha sido possível realizar apenas dois cortes (Figura 5), o que sugere menor possibilidade de utilização do pasto sob essa condição de manejo.
O comprimento final da folha, influenciado pela TApF, TAlF e taxa de alongamento de colmos (TAlC), foi maior nas plantas cortadas após o aparecimento de 5 folhas novas por perfilho durante a rebrotação (Figura 5), fato condizente com a maior altura pré-corte registrada sob aquelas condições (Figura 4B). A taxa de alongamento foliar está diretamente relacionada com o comprimento final da folha, enquanto o inverso acontece com a TApF (Lemaire \& Chapman, 1996).

A densidade populacional de perfilhos, influenciada pela TAlC e TApF (Figura 5), foi maior quando as plantas foram cortadas após o surgimento de três folhas novas por perfilho, corroborando com a teoria de que maior número de 
perfilhos pequenos são produzidos quando pastos são submetidos a regimes frequentes de desfolhação (Grant et al., 1983; Sbrissia et al., 2001) como forma de garantir máximo aproveitamento da luz incidente. Por outro lado, a remoção do meristema apical (Chapman \& Lemaire, 1993) nas plantas cortadas segundo o intervalo de corte mais longo (cinco folhas surgidas por perfilho) pode ter resultado em morte de perfilhos. O déficit de carbono promovido pela competição por luz em pastos manejados com maior intervalo de corte também pode ter contribuído para a mortalidade de perfilhos, uma vez que maior quantidade de carbono é alocada preferencialmente para perfilhos mais antigos em detrimento dos jovens em desenvolvimento (Davies et al., 1983).

Alterações na temperatura ou na qualidade da luz podem produzir alterações no índice de área foliar, no tamanho das folhas (CFF), no número de folhas vivas por perfilho (NFV) e na densidade populacional de perfilhos (DPP), como demonstrado por Lemaire \& Agnusdei (2000). Assim, as diferenças registradas em comprimento final da folha e densidade populacional de perfilhos entre as alturas de corte testadas (Figura 6) correspondem a respostas plásticas das plantas à severidade de corte utilizada (15 ou $30 \mathrm{~cm}$ ), as quais foram conseqüência de alterações em TAlC e TApF (Figura 6).

Plantas cortadas a $15 \mathrm{~cm}$ de altura apresentaram menor alongamento de colmos e maior TApF (quando combinada ao intervalo de cinco folhas surgidas por perfilho), o que resultou em folhas mais curtas (Figura 6), menor altura précorte (Figura 4A) e maior densidade populacional de perfilhos.

A taxa de alongamento de colmos, além de afetar diretamente a densidade populacional de perfilhos e o comprimento final da folha, pode ser utilizada como indicador do controle ou não do acúmulo desse componente pelo manejo do pastejo, cujo crescimento constitui-se em característica desfavorável no sistema de produção em pasto, pois representa barreira física ao consumo voluntário dos animais em pastejo, afetando a capacidade de apreensão de forragem (Hodgson, 1990). Assim, a menor altura de corte foi mais eficiente em controlar a TAlC, corroborando com os resultados obtidos por Trindade et al. (2007), que recomendaram a manutenção de um resíduo de $15 \mathrm{~cm}$ para manejo do capim-marandu sob pastejo rotativo.

Plantas cortadas a $15 \mathrm{~cm}$ apresentaram também menor taxa de senescência foliar que aquelas cortadas a $30 \mathrm{~cm}$ (0,062 e 0,119 cm/perfilho.dia, respectivamente; $\mathrm{P}=0,0107)$, característica que está associada diretamente com o acúmulo de material morto, redução da eficiência de colheita e do valor nutritivo da forragem produzida (Carnevalli et al., 2006).
A partir desses resultados pode-se inferir que a altura de corte de $15 \mathrm{~cm}$ favoreceria a maior eficiência de utilização dos pastos de capim-marandu, uma vez que permitiu maior controle do crescimento e desenvolvimento de colmos, menor senescência de folhas, além de garantir maior densidade populacional de perfilhos (Figura 6), sugerindo maior acúmulo líquido de lâminas foliares.

\section{Conclusões}

A maior eficiência de utilização do capim-marandu é alcançada quando o capim é manejado com resíduo de $15 \mathrm{~cm}$, aliado a cortes mais frequentes, três ou quatro folhas surgidas por perfilho. Dessa forma, a participação de lâminas foliares na produção total de forragem é elevada, principalmente em razão da maior densidade populacional de perfilhos. Quando é manejado com intervalo de corte de três folhas surgidas, o pasto requer menor quantidade de tempo para recuperação após o corte, independentemente do resíduo de 15 ou $30 \mathrm{~cm}$, o que poderá garantir maior eficiência ao sistema de produção animal em pasto.

\section{Agradecimentos}

Aos colegas do Programa de Pós-graduação em Zootecnia da UFV, Kênia Marcelino, Anderson Zanine e Bruna Adese, e aos estagiários Henrique Parente, Wilton Ladeira da Silva e Daniela Rezende, pela colaboração na condução do experimento.

\section{Referências}

CARNEVALLI, R.A.; DA SILVA, S.C.; BUENO, A.A.O. et al. Herbage production and grazing losses in Panicum maximum cv. Mombaça under four grazing managements. Tropical Grasslands, v.40, p.165-176, 2006.

CHAPMAN, D.F.; LEMAIRE, G. Morphogenetic and structural determinants of plant regrowth after defoliation. In: BAKER, M.J. (Ed.) Grasslands for our world. Wellington:SIR Publishing, 1993. p.55-64.

DAVIES, A.; THOMAS, H. Rates of leaf and tiller production in young spaced perennial ryegrass plants in relation to soil temperature and solar radiation. Annals of Botany, v.57, p.591-597, 1983.

DEREGIBUS, V.A.; SANSHEZ, R.A.; CASAL, J.J. et al. Tillering responses to enrichment of red light beneath the canopy in humid natural grassland. Journal of Applied Ecology, v.22, p.199-206, 1985.

EMPRESA BRASILEIRA DE PESQUISA AGROPECUÁRIA EMBRAPA. Sistema brasileiro de classificação de solos. Brasília, 1999. 412p. (Produção de Informação).

GRANT, S.A.; BARTHRAM, G.T.; TORVELL, L. et al. Ward management, lamina turnover and tiller population density in continuously stocked Lolium perenne L. dominated sward. Grass and Forage Science, v.38, p.333-344, 1983. 
HODGSON, J. Grazing management: science into practice. New York: John Wiley and Sons, 1990. 203p.

LEMAIRE, G.; AGNUSDEI, M. Leaf tissue turn-over and efficiency of herbage utilization. In: LEMAIRE, G.; HODGSON, J.; MORAES, A. et al. (Eds.) Grassland ecophysiology and grazing ecology. Wallingford: CAB International, 2000. p.265-288.

LEMAIRE, G.; CHAPMAN, D. Tissue flows in grazed plant communities. In: HODGSON, J.; ILLIUS, A.W. (Eds.) The ecology and management of grazing systems. Wallingford: CAB International, 1996. p.3-36.

LUPINACCI, A.V. Lançamento de cultivares de plantas forrageiras: uma visão crítica. In: PEIXOTO, A.M.; MOURA, J.C.; DA SILVA, S.C. et al. (Eds). In: SIMPÓSIO SOBRE MANEJO DE PASTAGENS, 20., Piracicaba. Anais... Piracicabal: FEALQ, 2003. p.83-104.

MARCELINO, K.R.A.; NASCIMENTO JÚNIOR, D.; DA SILVA, S.C. et al. Características morfogênicas e estruturais e produção de forragem do capim-marandu submetido a intensidades e freqüências de desfolhação. Revista Brasileira de Zootecnia, v.35, n.6, p.2243-2252, 2006.

MATTHEW, C.; ASSUERO, S.G.; BLACK, C.K. et al. Tiller dynamics of grazed swards. In: SIMPÓSIO INTERNACIONAL GRASSLAND ECOPHYSIOLOGY AND GRAZING ECOLOGY, 1., 1999, Curitiba. Anais... Curitiba: UFPR, 1999. p.109-133.

NELSON, C.J. Shoot morphological plasticity of grasses: Leaf growth vs. Tillering. In: LEMAIRE et al. (Ed.) Grassland ecophysilogy and grazing ecology. Wallingford: CAB International, 2000. p.101-126.
SBRISSIA, A.F.; DA SILVA, S.C.; CARVALHO, C.A.B. et al. Tiller size/population density compensation in Coast cross grazed swards. Scientia Agricola, v.58, n.4, p.655-665, 2001.

SBRISSIA, A.F.; DA SILVA, S.C. O ecossistema de pastagens e a produção animal. In: MATTOS, W.R.S. (Ed.). A produção animal na visão dos Brasileiros. Piracicaba: Sociedade Brasileira de Zootecnia, 2001. p.731-754.

SBRISSIA, A.F.; DA SILVA, S.C.; NASCIMENTO JÚNIOR, D. Ecofisiologia de plantas forrageiras e o manejo do pastejo. In: SIMPÓSIO SOBRE MANEJO DA PASTAGEM, 24., 2007, Piracicaba. Anais... Piracicaba: FEALQ, 2007. p.153-176.

SOUZA-JÚNIOR., S.J. Estrutura do dossel, interceptação de luz e acúmulo de forragem em pastos de capim-marandu submetidos a estratégias de pastejo rotativo por bovinos de corte. 2007. 122f. Dissertação (Mestrado em Agronomia Ciência Animal e Pastagens) Escola Superior de Agricultura "Luiz de Queiroz", Piracicaba.

STATISTICAL ANALYSES SYSTEM - SAS. SAS/STAT User's guide statistics. versão 6. 4.ed. Cary: v.1,2, 1996. 1014p.

THORNTHWAITE, C.W.; MATHER, R.J. The water Balance. New Gersey: Laboratory of Climatology, 1955. v.8, 104p.

TRINDADE, J.K.; Da SILVA, S.C.; SOUZA-JÚNIOR, S.J. et al. Composição morfológica da forragem consumida por bovinos de corte durante o rebaixamento do capim-marandu submetido a estratégias de pastejo rotativo. Pesquisa Agropecuária Brasileira, v.42, n.6, p.883-890, 2007. 